\title{
INTERVENÇÕES URBANAS A PARTIR DE INVESTIMENTOS DO PROGRAMA DE ACELERAÇÃO DO CRESCIMENTO (PAC): A RETERRITORIALIZAÇÃO DOS MORADORES DO ENTORNO DA OBRA CONTORNO NORTE DE MARINGÁ-PR URBAN INTERVENTIONS BASED ON INVESTMENTS FROM THE GROWTH ACCELERATION PROGRAM (PAC): THE RETERRITORIALIZATION OF THE RESIDENTS OF THE NORTH CONTOUR IN MARINGÁ-PR
}

\section{Adriano Aparecido de Oliveira}

Mestre em Administração (Universidade Estadual de Maringá - UEM), Professor Mediador EAD - Unicesumar - Cursos de Administração e Processos Gerenciais. Professor do Ensino Presencial (Unicesumar) e Professor Formador do Ensino à Distância (Unicesumar), UniCesumar, Brasil.

Data de recebimento: 14-12-2016 Data de aceite: 05-09-2017

\section{Priscilla Borgonhoni Chagas}

Professora Adjunta do Departamento de Administração da Universidade Estadual de Maringá. Doutora em Administração, na área de concentração Estudos Organizacionais na Universidade Federal do Rio Grande do Sul. Mestre em Administração pela Universidade Estadual de Londrina, Universidade Estadual de Maringá, Brasil.

\section{William Antonio Borges}

Professor Adjunto no Departamento de Administração, na Universidade Estadual de Maringá (UEM). Doutor em Administração Pública e Governo pela FGV/EAESP (2013), Universidade Estadual de Maringá, Brasil.

\section{Julia Silva Gonçalves}

Mestre em Administração na Universidade Estadual de Maringá, Universidade Estadual de Maringá, Brasil.

\section{RESUMO}

O presente artigo tem por objetivo compreender como ocorreu a reterritorialização, pelos moradores, de dois bairros fronteiriços a uma obra de grande magnitude - o Contorno Norte em Maringá (PR), realizada com recursos do Programa de Aceleração do Crescimento (PAC). Para tanto, o artigo apresenta conceitos relativos à produção do espaço urbano e território e caracteriza-se como qualitativo e descritivo. Foram realizadas entrevistas semiestruturadas com quatorze moradores e um representante do poder público municipal, além de pesquisa documental e bibliográfica. Esses dados foram analisados por meio da análise de conteúdo. Ao tratar da reterritorialização, foi possível concluir que os moradores sentem muita diferença no que diz respeito ao território em que viviam antes da construção da obra. Atualmente, eles relatam que se sentem excluídos do restante da população citadina e reconhecem diversos problemas socioespaciais, vistos por eles como um reflexo direto da construção da referida obra.

Palavras-chave: Produção do Espaço Urbano. Território. Programa de Aceleração do Crescimento. Contorno Norte.

\section{ABSTRACT}

The objective of this article is to understand the reterritorialisation by residents of two frontier districts of a great magnitude construction - the North Contour in Maringá (PR), carried out with funds from the Growth Acceleration Program (PAC). For this, the article presents concepts related to the production of the urban space and territory and is characterized as qualitative and descriptive. Semi-structured interviews were conducted with fourteen residents and one representative of the municipal public authority, as well as documental and bibliographical research. These data were analyzed through content analysis. It was possible to conclude that the inhabitants feel a lot of difference with respect to the territory in which they lived before the construction of the work. Nowadays, they report that they feel excluded from the rest of the city population and recognize several socio-spatial problems, which they see as a direct reflection of the construction of this construction.

Keywords: Production of Urban Space. Territory. Growth Acceleration Program. North Contour.

Endereço dos autores:

Adriano Aparecido de Oliveira adriano_pdu@hotmail.com
Priscilla Borgonhoni Chagas priscillachagas@gmail.com
William Antonio Borges waborges@uem.br
Julia Silva Gonçalves gonçalves.julia@gmail.com 


\section{INTRODUÇÃO}

A produção do espaço constitui um elemento central da problemática do mundo contemporâneo. As discussões sobre a temática ganharam força nos últimos anos devido à dinâmica do processo de acumulação capitalista, com destaque para a justificativa das ações do Estado em direção à criação dos fundamentos da reprodução, bem como do ângulo da (re)produção da vida, que se realiza em espaços-tempos delimitados reais e concretos (CARLOS; SOUZA; SPOSITO, 2013).

Carlos (2013) explica que o espaço urbano é, então, uma abstração a qual envolve a reprodução das relações contraditórias sociais das cidades e pode ser definida ainda como condição e meio para instituição das relações sociais, revelando as condições da vida cotidiana e o modo com que a sociedade se apropria do espaço que utiliza para a sua produção. Para Lefèbvre (1974), esse espaço não é um objeto específico, ou um produto, ou simplesmente resultado de um único processo, mas refere e apreende produtos e relações de coexistência e simultaneidade, relações de convivência e de coincidência, ordem e desordem. Essas ações são complexas e derivadas da dinâmica de acumulação capitalista, das necessidades mutáveis de reprodução das relações de produção e dos conflitos de classe que delas emergem.

Dessa forma, a apropriação e dominação do espaço urbano representam contradições e conflitos que refletem no espaço. Isso vem a caracterizar, assim, a materialização do espaço como produto comerciável, uma vez que faz a vida cotidiana tornar-se alvo de especulação capitalista apropriada pelos agentes sociais os quais, por meio do opor- tunismo, desejam adquirir algum tipo de vantagem pela lógica cumulativa de capital, em função da racionalidade limitada de outros agentes.

Sendo assim, o espaço é uma realidade que está em constante processo de transformação, em função da construção do espaço coletivo que se inicia na apropriação, transformação e utilização do território. O espaço, assim, produz uma mudança social que origina territórios e acompanha sua evolução, o que caracteriza o passado, o presente e o futuro, por meio de forças que influenciam na territorialização, desterritorialização e reterritorialização. Portanto, espaço e território são conceitos chaves, complementares e interdependentes.

O estudo de territórios é uma abordagem que vem sendo explorada recentemente por diversas áreas do conhecimento. Nos Estudos Organizacionais tem por potencial explicar, por exemplo, a territorialização (T), desterritorialização (D) e reterritorialização (R), caracterizado nesse estudo como processo T-D-R. No primeiro citado o território é compreendido como o enraizamento; no segundo, ou seja, no de desterritorialização, há o rompimento ou deslocalização e, no último - o movimento de reterritorialização há uma compreensão acerca das relações de poder, por meio de uma nova forma de ocupação do espaço vivido. A análise desse processo permite compreender a dinâmica das cidades no que tange à lógica capitalista na ocupação e produção territoriais. Assim, os territórios, segundo Souza (2012), existem e são construídos e descontruídos nas mais diferentes escalas e tempos, por exemplo, de uma rua para um Estado ou país e em séculos, anos, meses ou dias, podendo ter um caráter permanente ou cíclico. 
É neste contexto que se justifica a escoIha do objeto deste estudo: o Contorno Norte de Maringá (PR), já que este compreende os diferentes reflexos de uma obra de grandes proporções e influencia na reterritorialização dos moradores dos bairros fronteiriços ao empreendimento. A obra planejada pelo Departamento de Estradas e Rodagens do Estado do Paraná (DERPR) faz parte do Programa de Aceleração do Crescimento (PAC), lançado em 2007 no governo de Luiz Inácio Lula da Silva. A obra foi realizada em duas etapas, em que a primeira foi iniciada em dezembro de 2008; e a segunda, em junho de 2012 (BRASIL, 2015). Assim, obra foi finalizada em 31 de outubro de 2014, com $17,2 \mathrm{Km}$ de extensão, com orçamento previsto de $\mathrm{R} \$ 193.450 .000,00$, mas atingindo orçamento final de $R \$ 412.000 .000,00$ (BRASIL, 2015).

A justificativa principal para a construção do Contorno era eliminar os problemas existentes em outra avenida (Avenida Colombo), desviando carros e caminhões para região norte da cidade, permitindo maior mobilidade nas vias centrais. Mas tal objetivo não condiz com o resultado desta intervenção urbana, pois o acesso dos moradores dos bairros fronteiriços às marginais do Contorno ficou restrito e adicionado ao processo de segregação urbana com a implantação de bairros destinados à população de baixa renda, refletiu na vida das pessoas que ali residem, por instalar uma obra de tal magnitude em uma área que contempla a malha urbana devido ao crescimento e expansão da cidade para a região norte (FONTANA; VALLOTA, 2014).

A partir destas concepções, o objetivo do presente artigo é compreender como ocorreu a reterritorialização, pelos moradores, de dois bairros fronteiriços ao Contorno Norte (Conjunto Hor- tência e Conjunto Thaís), após o início das obras. Para tanto, esse artigo está organizado em cinco seções, além desta introdução. As duas seções a seguir abordam as bases conceituais que nortearam e fundamentaram o estudo. Em seguida, são apresentados os procedimentos metodológicos utilizados no desenvolvimento da pesquisa, seguido pela análise e interpretação dos resultados obtidos. Por fim, são traçadas as considerações finais do estudo, apresentando também novas reflexões sobre a temática.

\section{PRODUÇÃO DO ESPAÇO URBANO}

O espaço urbano é um local no qual as pessoas estabelecem as relações afetivas, ligando os grupos sociais entre si. As cidades surgem das atividades humanas socialmente organizadas, sendo a produção social de expressão espacial e territorial das sociedades que elas abrigam e expressando as contradições e os antagonismos da sociedade em geral.

Assim, para Corrêa (1989) o espaço urbano é a justaposição de vários usos da terra, simultaneamente fragmentado e articulado, uma vez que cada uma das partes mantém relações espaciais com as demais. O espaço urbano também é um reflexo da sociedade, uma vez em que nele se observa a complexa estrutura social em classes, a desigualdade e a segregação presentes na divisão das áreas residenciais. Em última instância, também é condicionante da sociedade, por meio do papel que as obras fixadas pelo homem desempenham na reprodução das condições de produção e das relações de produção (CORRÊA, 1989). Sendo assim, o espaço urbano é um produto social, um conjunto de símbolos, resultado de múltiplas 
ações de agentes concretos que se acumulam ao longo do tempo. Essas ações são complexas e derivadas da dinâmica de acumulação capitalista, das necessidades mutáveis de reprodução das relações de produção e dos conflitos de classe que delas emergem.

Destarte, a produção do espaço resulta da ação sistemática e intencional dos agentes sociais, caracterizada pela complexidade e por processos contínuos e descontínuos de organização. Constituem-se como os agentes produtores do espaço urbano, o Estado, os proprietários dos meios de produção, os proprietários fundiários, os promotores imobiliários e os grupos sociais excluídos (CORRÊA, 1989).

Na busca de valorização do tecido urbano, os agentes produtores deste espaço urbano privado (re)produzem uma dinâmica que tem o intuito de acumular capital por meio da sua territorialização, em que a terra se apresenta como mercadoria, a qual se vincula a um processo de especulação no intuito de se auferir uma maior renda (LEITÃO, 1999). Ao mesmo tempo, o Estado regulamenta a ocupação do solo urbano por meio da legislação em vigor, tendo em vista um desenvolvimento meIhor estruturado do território.

Dentre todos os agentes, o Estado é o que usufrui de instrumentos mais amplos para atuar na produção do espaço. Alguns instrumentos foram enfatizados por lei, como a do Estatuto da Cidade (Lei No 10.257/2001); a desapropriação da terra para utilização pública; a precedência da compra da terra; o controle e limitação do preço do solo urbano; a limitação da terra para construção; a cobrança de impostos; a implantação de infraestrutura; o crédito imobiliário para construção de habitação ou compra do solo. Nesse contexto, fica evidente o caráter regulatório, em que o Estado define o que pode ser feito na cidade, por meio dos Planos Diretores e induz a expansão do perímetro urbano, ou seja, o crescimento da cidade (COELHO, 2012).

Dessa forma, a apropriação e dominação do espaço urbano representam contradições e conflitos que refletem no espaço. Isso vem a caracterizar, assim, a materialização do espaço como produto comerciável, uma vez que faz a vida cotidiana tornar-se alvo de especulação capitalista apropriada pelos agentes sociais os quais, por meio do oportunismo, desejam adquirir algum tipo de vantagem pela lógica cumulativa de capital, em função da racionalidade limitada de outros agentes.

Diante dessa constatação do espaço - visualizado como mercadoria a partir da conceituação de espaço mediado pelos agentes sociais, o próximo passo refere-se ao fato de que é necessário buscar outras dimensões de análise da realidade. Dessa forma, objetiva-se iluminar conflitos que realçam o comportamento da sociedade, buscando fundamentos da produção do espaço como mercadoria alienada à sua forma percebida e aceita pela sociedade, mesmo que de maneira inconsciente.

$E$, contrapondo o sentido de espaço à noção de território, já há uma relação à exterioridade do sujeito no que tange ao espaço, pois não existe território sem sujeito e tal definição de espaço e território permite analisar o papel ativo na configuração espacial. Desta maneira, torna-se fundamental iluminar o processo de territorialização, desterritorialização e reterritorialização, sobretudo ocorrido a partir de intervenções urbanas. Nesse sentido, o conceito de território e o processo T-D-R são discutidos a seguir. 


\section{OS ESTUDOS SOBRE TERRITÓRIO}

Nessa seção, o objetivo é apresentar as principais definições acerca de território, a partir de distintas correntes. É essencial entender que, apesar de território e espaço não serem sinônimos, esses conceitos são indissociáveis, pois o território é formado a partir do espaço e, portanto, o estudo deve pressupor que a análise do território deve ter como referência o espaço - daí a indissociabilidade entre os conceitos de território e espaço.

Dessa forma, o espaço é uma realidade que está em constante processo de transformação, em função da construção do espaço coletivo que se inicia na apropriação, transformação e utilização do território. E, assim, o espaço produz uma mudança social que origina territórios e acompanha sua evolução, o que caracteriza o passado, o presente e o futuro, por meio de forças que influenciam na territorialização, desterritorialização e reterritorialização.

Para se compreender território, antes é necessário buscar elementos constitutivos do conceito de espaço e também da relação espaço-tempo. O termo território vem do latim, territorium, que deriva de terra e significa a apropriação de um pedaço de terra. Território tem a sua noção atrelada à chamada Geografia Clássica e, durante um período de tempo, esteve ligado à sua concepção de território nacional, onde o Estado tinha o poder de determinar as fronteiras físicas. Na sua origem propriamente dita, a noção de território está vinculada a uma abordagem clássica da geografia politica, por meio da obra de Friedrich Ratzel, do final do século XIX - obra esta centrada no Estado-Nação como unidade representativa do Estado, que seria o espaço no qual sua soberania é exercida e tem a sua noção elencada a limite, sendo uma consequência direta do poder exercido pelo Estado (SAQUET, 2009).

A partir da década de 1960 e 1970, surgiram novos movimentos na Geografia os quais redescobriram o conceito de território e, aos poucos, esse movimento de renovação passou a acompanhar as mudanças socioespaciais pautadas principalmente na corrente de pensamento do materialismo histórico dialético e no nível do pensamento filosófico, trazendo múltiplas interpretações de análise de território. De acordo com Saquet (2009), isto significa dizer que essa redefinição foi uma superação da geografia clássica. E, assim, a definição de território é marcada por uma nova conotação. A obra "Por uma geografia do poder", de Claude Raffestin (1993), publicada no ano de 1980, contribuiu de forma expressiva com a geografia brasileira. Raffestin (1993), que se pauta referencialmente em Michel Foucault, trata o território de forma correlacional com o poder, ao entender que a atuação do Estado está intimamente ligada ao poder, incluindo as relações com a sociedade.

A discussão do conceito de território, no cenário brasileiro, passou por um processo de expansão e qualificação, centrado nos conceitos de territorialidade, que surgiram principalmente a partir do biênio de 1992 e 1993. No Brasil, muitos fatores internos e externos ao país impulsionaram os estudos territoriais na geografia, na economia, na sociologia e, mais recentemente, nos estudos organizacionais, em uma tentativa de compreender fenômenos e processos relacionados às redes de circulação e comunicação, à identidade e a relações de poder (SAQUET, 2013).

$E$, desta maneira, dentro de um contexto da materialidade/imaterialidade, algumas obras contri- 
buíram decisivamente para o avanço da abordagem territorial no Brasil. Entre elas, a de Milton Santos, que contempla uma perspectiva materialista, argumentando principalmente em favor do espaço geográfico; também a de Rogério Haesbaert, que produz uma compreensão a qual identifica o território como integrador ou hibrido entre as dimensões materiais e idearia de território e considera os aspectos culturais e políticos; e, por fim, a obra de Saquet, a qual busca possibilitar a apreensão dos aspectos da relação matéria-ideia, destacando os aspectos políticos e econômicos (SAQUET, 2013).

Assim, evidenciando separadamente cada um dos autores mencionados, Santos (1994) inicia os trabalhos, destacando o conceito de território usado em uma abordagem econômico-material a qual amplia a discussão para além da abordagem areal ou restrita somente à compreensão de território como Estado-Nação, enaltecendo, assim, o uso e o controle social. Desse modo para o autor, território significa objetos, ações e a constituição de redes e pode ser compreendido como sinônimo de espaço geográfico socialmente organizado (SAQUET, 2013).

Para Haesbaert (1994) o território possui múltiplas dimensões. Tal autor reconhece o processo de dominação e de apropriação na construção de território, contemplando os aspectos objetivos e subjetivos. Ainda segundo o autor, existe o domínio social, o político e o econômico na compreensão da abordagem territorial, as relações de poder estão estabelecidas pelo Estado- Nação, até mesmo na multidimensionalidade das relações sociais. E, portanto, as relações sociais é que, de fato, condicionam e constituem o território (HAESBAERT, 1994).

E, assim na compreensão de território, Haes- baert (2012) afirma que o processo de produção do espaço contempla sempre e concomitantemente, a desterritorialização e a reterritorialização. Assim, fica claro o avanço na compreensão de território, pois, para o autor, a abordagem territorial precisa ser analisada do ponto de vista das dimensões sociais: a desterritorialização, econômica e política - e a territorialização - política e cultural.

Dessa forma, o autor reconhece claramente o movimento de força de trabalho no território, por exemplo, força excluída e reterritorializada, o que efetiva a constituição de redes de circulação e de comunicação, como elementos pertinentes à desterritorialização e à reterritorialização, contribuindo assim, para a definição da coesão e da unidade, da identidade e do regionalismo (HAESBAERT, 2012).

$\mathrm{E}$, nesse aspecto relativo, existe uma clara separação entre os fatores determinantes da territorialização, pois, para Haesbaert (2012), o território significa a coesão de identidade e também a apropriação e o ordenamento político. Já as redes de circulação de capital têm o caráter desterritorializador, condicionando a perda do território, ou seja, o capital depõe claramente a favor dos interesses de terceiros e abre margem para novas formas de ocupação do território. Assim sendo, pessoas são obrigadas a buscar novas formas de reocupar o espaço.

Para Haesbaert (2012), o território tem um domínio politicamente estruturado e uma apropriação simbólica por certos grupos de interesses que formam alianças e coligações, determinando ações sobre certos grupos sociais que ocupam aquele espaço da vida. E, nesse sentido, o autor avança na conceituação de território, elencando a desterritorialização como processo que está diretamente vinculado à modernização e à globalização, ou seja, 
um reflexo do capitalismo. Assim, a desterritorialização significa a destruição de antigos territórios, mediante a reapropriação do espaço em redes. A reterritorialização, por sua vez, corresponde a uma nova maneira de se apropriar de forma simbólica ou política do espaço, e também inclui redes.

Mais recentemente, Haesbaert (2004) retoma o conceito de território, no sentido que ele denomina de multiterritorialidade, isto é, múltiplas formas vividas por diferentes grupos sociais, em distintas escalas de interação, ocorrendo, por exemplo, de uma rua para uma cidade, de um dia para um ano etc. Assim, retomando esse conceito de multiterritorialidade, o autor destaca, de forma histórica, as dimensões da economia, da política e da cultura sobre um determinado território. Há, portanto, evidentemente, uma ênfase às redes de comunicação e de circulação. São as relações de poder que, de fato, efetivam as relações de território. O território neste sentido contempla uma forma de dominação política e econômica e também de apropriação simbólico-cultural, sendo, portanto, multifuncional e multiescalar. Para Haesbaert (2004), podem existir territórios zona, territórios rede e os aglomerados de exclusão, numa conjunção de perspectiva área-rede, rede-rede e rede-lugar.

Por sua vez, Saquet (2009) estabelece inicialmente algumas ideias centradas no conceito de produção social do espaço. Por essa perspectiva território remete a um lugar de vida, construído historicamente, área sob a ordem do capitalismo. Assim, o autor dá ênfase aos elementos e processos econômicos e contempla também as reações políticas, econômicas e culturais, inerentes ao cotidiano de lutas.
Saquet (2009) explica que existe uma relação direta entre espaço e território, mas estes correspondem a dois níveis diferentes na vida cotidiana das pessoas e no pensamento científico. O espaço é uma realidade que envolve a natureza produzida pelas ações do homem, as quais, por sua vez, são mediadas pelo trabalho, o que produz aspectos históricos na configuração territorial. O espaço territorial é o exercício de poder de um Estado que, na forma política, utiliza de sua soberania para regular as ações de domínio patrimonial, propriedade e a vida social.

Nessa conjuntura, o processo territorialização-desterritorialização-reterritorialização (T-D-R) pode ser compreendido como um processo de relações sociais "um refazer de territórios, de fronteiras e de controles que variam muito conforme a natureza dos fluxos em deslocamento sejam eles fluxos de imigrantes, de mercadorias, de informação ou de capital" (HAESBAERT, 2007, p. 122). No entanto, é válido destacar que, para Saquet (2009), na desterritorialização o que já existe não deixa de existir, mas passa por uma evolução, adaptada às novas configurações territoriais.

O território, então, é considerado um produto histórico, com mudanças que ocorrem em um ambiente no qual se desenvolve uma sociedade. O território, portanto, significa apropriação social do ambiente, construído por meio de múltiplas variáveis recíprocas. O homem vive no espaço natural e social, habitat onde produz, vive e objetiva subjetivamente. O território é um espaço natural, social e historicamente organizado. Assim, pode ser percebido o território através deste processo (SAQUET, 2009).

Os conceitos de território e espaço tratados dessa maneira, segundo Saquet (2009, p. 82), "é, 
portanto, uma questão epistemológica, ontológica e política", pois a diferentes abordagens acerca de poder, território e territorialidade compreendem uma tentativa do autor em apresentar uma concepção multidimensional, reticular e histórica de território e territorialidade na dimensão social. Aparece em tela, então, a questão da produção e da gestão dos recursos ou da territorialidade.

Assumindo essa perspectiva, para Saquet (2009, p. 81), "o território é considerado produto de mudanças e permanências ocorridas num ambiente no qual se desenvolve um grupo social". Território pode ser definido assim como "apropriação social do ambiente; ambiente construído, com múltiplas variáveis e relações recíprocas" (SAQUET, 2009, p. 81). A apropriação do ambiente é expressa, dessa maneira, em termos sociais nas relações de poder.

No Brasil, além dos autores citados anteriormente, Marcelo Lopes de Souza (2012) reafirma o movimento de reterritorialização, como uma maneira multidimensional das relações de poder, ou seja, os territórios existem e são apropriados pelos indivíduos por meio das ações de poder; são construídos e desconstruídos nas mais diversas escalas, de uma rua para uma cidade em diferentes períodos de tempo. Os territórios são desconstruídos em escalas que podem considerar até séculos em caráter permanente ou ocorrer ciclos. Então, Souza (2012) considera que o território não é substrato, o espaço social em si, mas um campo de forças em que os indivíduos estabelecem relações de poder espacialmente delimitadas e operando sobre "um substrato referencial" (SOUZA, 2012, p. 97).

Assim, o autor considera que essas relações não podem ser descoladas do espaço; esse é o substrato que o autor revela nesse avanço teórico. O território, para Souza (2012), significa apropriação e dominação político-econômica, estratégica e varia por meio do tempo e do espaço em diferentes escalas, enquanto campo de forças. Portanto, o território significa materialidade que sustenta a vida determina as práticas espaciais, além de influenciar os processos identificatórios. É, assim, um campo de poder em que se projeta um substrato espacial; um processo social que envolve imaginário, conflitos políticos e o controle sobre o espaço. A territorialização, portanto, é resultado e condição dos processos sociais e espaciais; significa movimento histórico e relacional e contempla a multidimensionalidade, por tratar das desigualdades e das diferenças, sendo unitária, por meio das identidades.

Assim, nessa pesquisa, assume-se o conceito de território a partir das reflexões e ideias de Souza (2012), por iluminar as relações sociais em diferentes escalas espaciais e temporais e também porque representa uma visão abrangente e completa sobre território no âmbito urbano, permitindo a análise da reprodução de grupos sociais em um determinado lugar e em diferentes períodos de tempo. Vê-se que o conceito de território tratado por Souza (2012) refere-se às relações sociais e de poder projetado no espaço.

A conceituação de território utilizada por Souza (2012) está associada ao exercício do poder sobre outros homens na dominação do espaço. Sendo assim, território é uma realidade social materializada em um determinado espaço, sendo que pressupõe um espaço social, ou seja, quando um homem se apropria de um espaço, ele o territorializa e cria uma identificação com o local. Na apropriação de um espaço, forma-se um território 
delimitado pelas relações de poder que nesse espaço acontecem. Território é, para Souza (2012, p.78), "todo espaço definido e delimitado por e a partir das relações de poder" e, assim, "o poder é onipresente nas relações sociais; o território está, outro assim, presente em toda espacialidade social - ao menos, enquanto o homem estiver presente" (SOUZA, 2012, p. 95).

Além disto, Souza (2012) explica que as relações de poder acontecem em diversas escalas e podem estar elencados a diversos agentes produtores do espaço. Dessa forma, o território pode apresentar diversas territorialidades entre homem e o espaço no mesmo espaço, conforme explicitado na territorialização, desterritorialização e reterritorialização, ou seja, as territorialidades podem ser geradoras de territórios e passiveis de transformação. Com essas contribuições de Souza (2012), é possível compreender os reais reflexos que a interação com outros homens pode reproduzir.

Nesse contexto, o território assume posição central na presente pesquisa, por entender-se que a territorialidade contempla os modos de vida dos indivíduos e, sendo assim, compreende o território como uma abordagem importante nos Estudos Organizacionais, no que tange às ações de poder ligadas à produção do espaço urbano.

\section{PROCEDIMENTOS METODOLÓGICOS}

O presente estudo caracteriza-se como uma pesquisa qualitativa, uma vez que o seu objetivo não é reduzir a complexidade dos elementos, mas sim proporcionar o aumento da compreensão do contexto em que se encontra (FLICK, 2004).
Tal posicionamento leva ao entendimento dos fenômenos organizacionais, sob a perspectiva do comportamento e da interação dos indivíduos. Assume características descritivas, envolvendo principalmente a pesquisa documental, a bibliográfica e a pesquisa de campo, utilizada na coleta de dados. E, como os fenômenos são impregnados de significados que o ambiente Ihes proporciona, este rejeita todas as expressões quantitativas, numéricas e medidas.

Com relação ao campo de pesquisa, este corresponde à área conhecida como via Contorno Norte, situada na cidade de Maringá-PR. Tal via compreende um perímetro de malha viária nos extremos da cidade num total de 17,2 km, com início na saída da cidade de Sarandi (PR), e chegando até a saída para Paranavaí (PR). A escolha da área a ser investigada deu-se em função da representatividade da obra para a cidade, por seus reflexos para a população local e também por contar com recursos provenientes do Governo Federal, por meio do Programa de Aceleração do Crescimento (PAC).

O local de pesquisa com os moradores foi definido com base nos setores censitários do IBGE (2010) no entorno do Contorno Norte, o qual conta com aproximadamente 18.498 residências que fazem divisa com a via (IBGE, 2010). Guiando-se, então por esses setores censitários e levando em consideração a densidade demográfica e também os setores mais afetados pela construção da via Contorno Norte, a pesquisa com os moradores foi realizada nos bairros Jardim Hortência e Conjunto Thaís. Na figura abaixo, pode-se notar a localização de tais os bairros, que são cortados e fazem divisa com o Contorno Norte de Maringá (conforme observado na Figura 01). 
Figura 1 - Localização Conjuntos Thais e Hortência

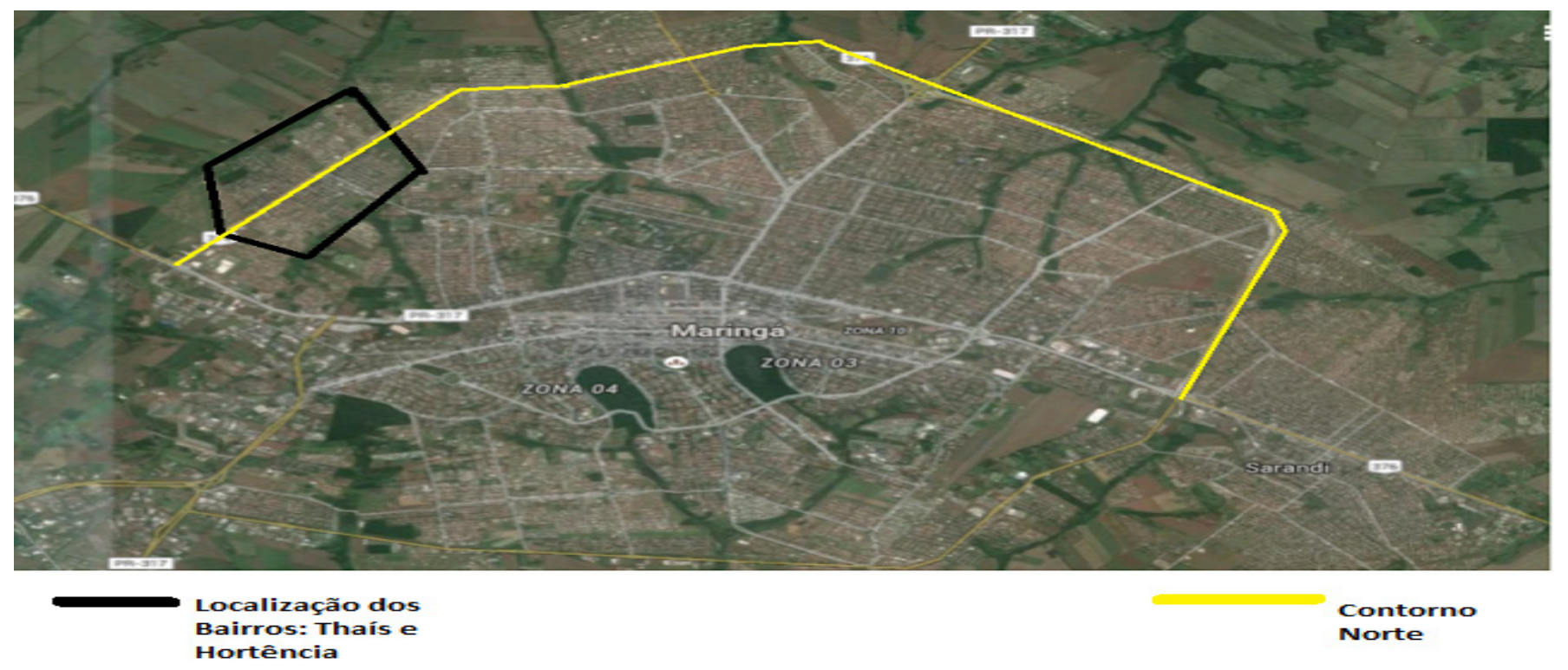

Fonte: Google Mapas (2016).

A coleta de dados foi realizada por meio de entrevistas individuais semiestruturadas com 14 moradores da região. Também foi entrevistado um representante do poder público municipal, responsável pela fiscalização e acompanhamento das obras do Contorno Norte de Maringá. Foi utilizado o conceito de "ponto de saturação", para a definição da quantidade de entrevistados, ou seja, o processo de seleção dos entrevistados foi interrompido, quando novas entrevistas não proporcionavam nenhuma variedade significativa para corroborar com os objetivos da pesquisa (BAUER; ARTS, 2013).

A coleta de dados secundários concretizou-se em bancos de dados, tais como: artigos, livros e relatórios de pesquisa. Como principais fontes de dados secundários, podem-se citar: (1) Instituto Brasileiro de Geografia e Estatística - IBGE; (2) Departamento Nacional de Infraestrutura e Transporte DNIT; (3) Programa de Aceleração do Crescimento - PAC; (4) Observatório das Metrópoles de Maringá - UEM. Segundo Minayo (2009), os dados secun- dários são aqueles que têm uma relação direta com o acontecimento registrado por meio de materiais já existentes.

Para a interpretação dos dados obtidos foi utilizada a técnica da Análise de Conteúdo, realizado a partir da transcrição integral das entrevistas. Segundo Bardin (1979), as técnicas para a análise de conteúdo organizam-se levando em consideração os seguintes itens: pré-análise, exploração do material, tratamento dos resultados obtidos e interpretação. Diante disso, nesta pesquisa, a pré-análise foi realizada por meio da definição do tema, conceituação teórica, construção dos objetivos e procedimentos metodológicos. E, além disso, também foi realizada a preparação do corpus da pesquisa, mediante a transcrição das entrevistas e organização dos dados secundários coletados, junto com a revisão bibliográfica. Na segunda fase, todos os dados foram codificados para a compreensão do texto. Dessa forma, no tratamento dos dados obtidos na pesquisa, foi aplicada a diversidade material 
resultante da comunicação verbal, estabelecida nas entrevistas semiestruturadas e nos dados secundários. O resultado oriundo das interações com os moradores e com o representante do poder público foi expresso por meio de recursos linguísticos orais e escritos. Além disso, a análise dos dados em documentos como jornais, textos e falas também compuseram esse processo.

Os dados coletados foram examinados mediante análise categorial, conforme explica Bardin (1979). Tal recurso consiste no desmembramento do texto em categorias agrupadas. A opção por esse procedimento de análise respalda-se no argumento de que esta é a melhor alternativa quando se quer estudar valores, opiniões, atitudes e crenças, por meio de dados qualitativos. Na próxima seção é retratado o processo T-D-R, ocorrido com a construção do Contorno Norte, em Maringá.

\section{A RETERRITORIALIZAÇÃO DOS BAIRROS HORTÊNCIA E CONJUNTO THAÍS, PELOS MORADORES, APÓS O INÍCIO DAS OBRAS DO CONTORNO NORTE}

Maringá foi criada em 10 de maio de 1947, como Distrito de Mandaguari, e elevada à categoria de município em 14 de novembro de 1951. Tratou-se de um projeto de ocupação inicialmente conduzido sob orientação da Companhia Melhoramentos Norte do Paraná. A cidade de Maringá foi planejada para se tornar um polo regional, assim como Londrina, Cianorte e Umuarama, todas localizadas na porção norte do estado do Paraná, onde predominava a economia cafeeira, como base e desenvolvimento (STAHLHOEFER; RODRIGUES, 2010).
Maringá nasceu a partir de um plano urbanístico, com representações simbólicas que enfatizam a sua imagem urbana e destacam um polo regional que se criava em uma região sem ocupação urbana anterior (ANDRADE; CORDOVIL, 2008).

As primeiras edificações na região norte da cidade de Maringá remetem a ações públicas e políticas adotadas ainda na década de 1950, quando se deu a primeira legislação urbanística na forma de Código de Posturas e Obras (Lei N³4/1959). Assim, o que se verificou na década de 1960 foi uma indiscriminada anexação de novos loteamentos aos limites da cidade, embora ainda existissem espaços vazios no plano inicial elaborado por Jorge de Macedo Vieira, porém, com um valor elevado, o que, certamente, contribuiu para situação de segregação urbana em direção à região norte da cidade de Maringá (ANDRADE; CORDOVIL, 2008).

A partir de 1979, com o crescimento e expansão da população urbana, houve a necessidade de aprovação de novos loteamentos que causaram extravasamento da cidade de Maringá, para suas extremidades. O Plano de Diretrizes Viárias, elaborado em 1979, possibilitou abertura de 54 novos loteamentos para a cidade de Maringá. O Parque Hortência I e II e o Conjunto Thaís estão entre esses loteamentos e são bairros que foram cortados pelo Contorno Norte. O fato é que esses bairros existem desde a década de 1980 e o projeto do Contorno Norte é proveniente da década de 1990, o que remete a uma falta de planejamento urbano na cidade de Maringá (TÖWS, 2015).

Isso remete ao fato de que o poder público legitimou tal obra sem as modificações necessárias. Ele considerou uma situação atual em relação ao projeto idealizado ainda na década de 1990, 
sobre um perímetro que atualmente contempla uma área povoada já na década de 1980 e com uma postura contraditória em relação à circunscrita em um determinado território, como retratada pela entrevistada $\mathrm{E} 2$ :

Esse contorno aí ó saiu no lugar errado, porque esse Contorno deveria ser mais no canto da cidade né, e saiu no meio e cortou nosso bairro e não tinha essa separação do lado de lá e do lado de cá (E2).

Território contempla materialidades e imaterialidades, que impõem ações e relações envolvendo os agentes sociais que produzem o espaço urbano, criando-o e recriando-o conforme suas necessidades. Para analisar a produção do espaço urbano e suas dinâmicas, é importante citar, como explica Corrêa (2013), a inclusão de práticas que determinam processos, os quais definem e configuram as cidades.

Considerar a participação de agentes sociais na produção do espaço é levar em conta que estes não só participam da produção, mas também estabelecem relações corriqueiras, como os elos de vizinhança e identidade com tal local, conforme cita (E3);

Eu mesma tinha uma amiga minha que mora do lado de lá, nossa ela gostava de vir para cá e eu ir para lá na casa dela, e hoje por causa do contorno a gente passa até seis meses sem se ver e só se encontra no mercado (E3).

Após a construção da via Contorno Norte, os próprios moradores fazem essa distinção de quem mora do lado da cidade de Maringá e quem mora do outro, evidenciando o deslocamento socioespacial da região. Por isso, é necessário compreender o espaço como suporte de análise do processo de produção do espaço urbano. Isso porque é no espaço que acontecem as relações de poder essência das relações de produção, tal como afirma (SOUZA, 2012).

E, assim, os primeiros reflexos são os sentimentos de invasão, exclusão e falta de apoio do Estado sobre o lugar, o que, de modo geral, gera reflexos negativos na vida das pessoas. No período em que se iniciou a construção da obra, uma grande quantidade de poeira e lama que sujava as casas com frequência era muito superior ao que, de fato, é normal. Foram relatadas também ocasiões em que faltava água na região, conforme detalha a entrevistada:

Você sabe o que é caminhões e caminhões trabalhando e jogando aquelas nuvens de terra na sua casa, tanto que meus pisos encardiram tudo, além de sempre faltar água e que não sabemos o porquê, eu ficava sem água dois a três dias e quando vinha só vinha um pouquinho e não dava para fazer nada e minha casa entupida de terra e eu precisava de água para lavar (E14).

Além disso, a utilização das máquinas pesadas, muitas vezes, madrugadas adentro, somadas ao aumento de circulação nas vias paralelas a obra, produziam barulhos excessivos, o que acabava com o "sossego" da população que residia no entorno, como descrito pela entrevistada (E10);

Dentro de casa, sempre trouxe um transtorno muito grande. Para assistir televisão, você 
pode colocar no último volume que não escutava nada (E10).

Nesse contexto, foi o morador do entorno da obra quem sofreu um processo de desterritorialização, ao perder suas referências econômicas, políticas e culturais perante o local vivido, tal como diz a moradora:

A cidade de Maringá eu amo e adoro a cidade, é muito boa, só que já pensei várias e várias vezes, gastei muito para reformar minha casa e agora passa um Contorno na frente do meu portão, e assim já pensei várias vezes em sair daqui (E10).

O processo de territorialização e, consequente, desterritorialização depende diretamente de novas relações entre sujeito e espaço. Tal sobreposição ocasiona novos conflitos, ordenando, assim, novos usos. O Contorno Norte de Maringá significou um momento de desterritorialização, pois houve a ruptura de laços culturais e sociais, o que, por conseguinte, territorializou novas áreas e reterritorializou outras, por meio de uma nova forma de ocupação, conforme pode ser interpretada na fala da (E10):

Aqui na nossa região não vai acontecer mais nada, desvalorizou e vou ver se eu vendo aqui para alguma borracharia né, olha o espaço morto que tem aqui (E10).

Assim, o que no início da obra era visto como uma possível melhoria para a população local tornou-se um grande transtorno, com uma barreira limitadora. Ao ser executado o projeto, alterações deveriam ter sido feitas, para que os problemas concentrados na Avenida Colombo (ruídos, poluição etc.) não fossem apenas transpostos para o lado norte da cidade, provocando múltiplos reflexos aos cidadãos que residem às margens da via expressa. Por conta disso, o acesso dos moradores dos bairros às marginais do Contorno ficou restrito (como pode ser visto na Figura 02 abaixo).

Figura 2 - Contorno Norte

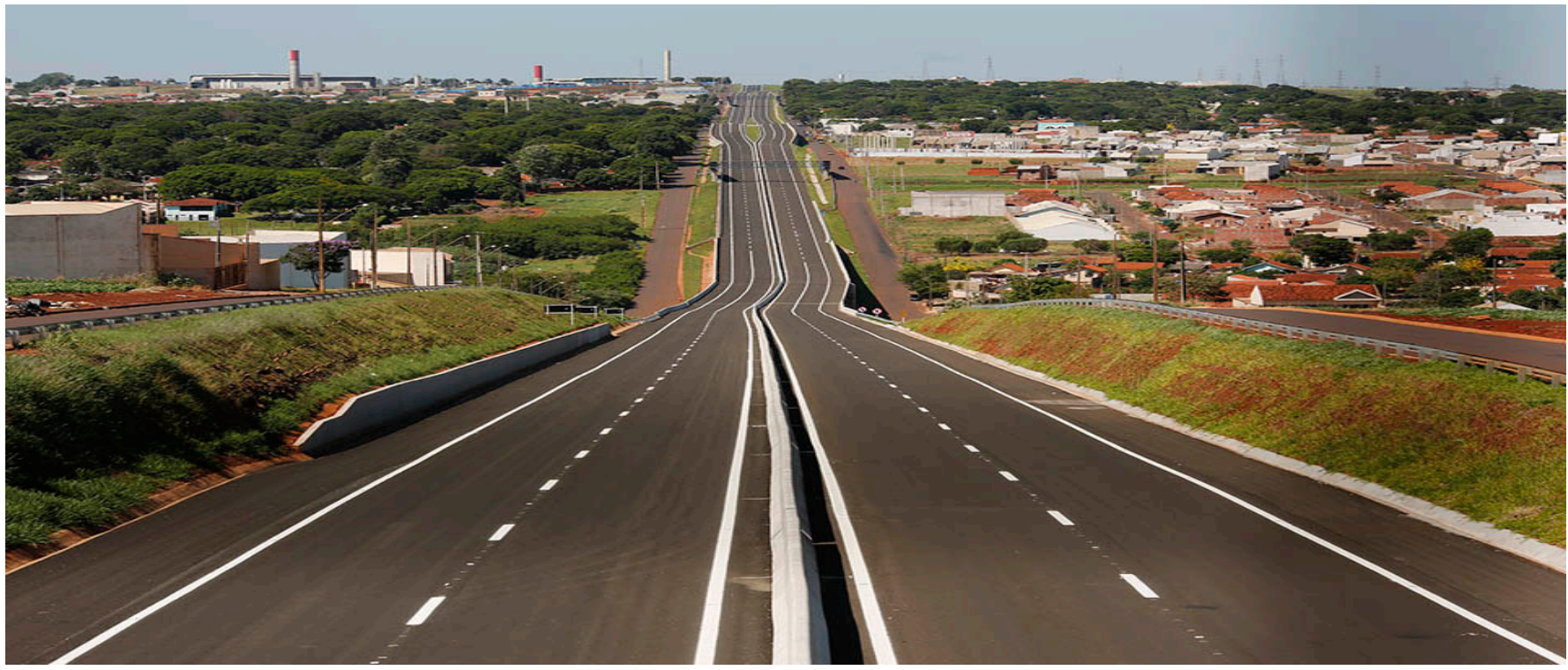

Fonte: Prefeitura Municipal de Maringá (2015). 
Nesse sentido, a construção da via provocou a desterritorialização da população do seu entorno, forçando essas pessoas a encontrarem outras formas de territorializar o local. E tal reterritorialização não é fácil, apesar de o antigo território ter modificado a paisagem, esta continua muito viva na memória e na identidade das pessoas, como explica (E14):

Eu sinto assim, por tudo que a gente viveu no começo e vive agora uma frustração, porque desvalorizou tudo com essa divisão da cidade (E14).

Os processos de desterritorialização provocados pela construção do Contorno Norte refletem diretamente na localização dos indivíduos no perímetro urbano, porém, fixando-se em um aglomerado de exclusão, como relata o morador (E6);

É como se fosse um pedaço de terra morta, né, do lado de cá, e dividiu a cidade praticamente e não tem sentido fazer um contorno dentro da cidade, como bloquear os dois lados? Isso não tem sentido (E6).

E, nesse contexto de desenvolvimento, Souza (2012) questiona: pode-se chamar "desenvolvimento" uma mudança em que se desconsideram os "efeitos colaterais" em termos econômicos, políticos e culturais? Sabe-se que não, já que os custos desse "desenvolvimento" são desastrosos, não só para os moradores, mas para toda a cidade, pois reflete na sub-urbanização.

Entende-se como território agora reterritorializado, no fato em questão, das famílias do entorno do Contorno Norte terem que se reorganizar em um local onde lhes foi imposto um modo de vida o qual thes é estranho. Assim, as pessoas precisam buscar novos modos de vida e tentar se acostumar com uma situação de desconforto, tal como afirma (E14):

Aqui em casa meu vidro fica sempre fechado, eu deixo o volume da minha televisão nos 100 e, apesar disso, você não ouve nada, tanto que estou pensando mudar minha casa para mudar o local da sala de estar (E14).

Os moradores da região também criticam a falta de consulta pública à população local. Segundo os moradores, em pouco tempo, os preços das moradias desvalorizaram cerca de $50 \%$ nas áreas próximas ao Contorno Norte. E, como reflexo desse processo, a classe trabalhadora que mora no local perde todos os investimentos realizados na casa, como explica a (E14);

Eu não sei mais o que dá para fazer aqui. É um pedaço de terra morta, de repente fazer um salão para alugar (E14).

Com isso, pode-se comprovar a ideia de que o Contorno Norte de Maringá foi mal planejado e serviu como um pretexto para valorizar a região central da cidade, mais especificamente a Avenida Colombo, em beneficio da acumulação de capital e levando em conta os interesses dos agentes imobiliários locais na área.

Dessa forma, estamos diante do que se denominou como processo T-D-R: a criação de territórios seria representada pela territorialização; a sua destruição (por mais que seja temporária) pela desterritorialização e a sua recriação pelos processos de reterritorialização (SOUZA, 2012). 
Nesta pesquisa, procurou-se relacionar a abordagem territorial proposta por Souza (2012) a outros conceitos importantes da geografia, no sentido de fundamentar tal abordagem e relacioná-la aos Estudos Organizacionais. Assim, entende-se que é pertinente se compreender os processos que envolvem a produção de territórios, os quais, necessariamente, contemplam múltiplas territorialidades no processo de territorialização, desterritorialização e reterritorialização de indivíduos e grupos sociais.

Portanto, as abordagens em torno do conceito de território, a partir das reflexões de Souza (2012), Haesbaert (2012; 2004) e Saquet (2009; 2013), apontam para a existência de diversos territórios (concretos e simbólicos) e territorialidades (individuais e coletivas) que se sobrepõem no espaço geográfico e contemplam a imaterialidade. As territorialidades são influenciadas pelas técnicas, pelo modo de produção e pelo capital, manifestando-se no comportamento, ou seja, nas ações de indivíduos e grupos sociais.

\section{CONSIDERAÇÕES FINAIS}

A cidade é um local de convivência entre os indivíduos, apresentando a concretização dos laços comunitários de um determinado grupo. Além disso, ela retrata o meio pelo qual a vida de uma determinada população se constitui por meio de políticas públicas aplicadas ao local, bem com a disponibilização dos serviços públicos. Assim, é necessário olhar para além dessas construções arquitetônicas e entender que tais alterações se relacionam diretamente com a vida de muitos moradores de seu entorno e também com a da população citadina com um todo. Nesse sentido, buscou-se a com- preensão de como a construção da obra Contorno Norte em Maringá afetou a organização das pessoas, a vida dos moradores que residem em bairros fronteiriços à via. E é neste aspecto que esta pesquisa proporciona um avanço nas discussões dos Estudos Organizacionais na medida em que busca o entendimento de como os moradores das imediações sentem-se com relação a tal construção, analisando as modificações ocasionadas de forma material ou simbólica e revelando os aspectos econômicos, culturais e políticos envolvidos.

Por meio do estudo foi possível revelar que a produção do espaço urbano da cidade de Maringá é influenciada pelos principais promotores imobiliários da cidade em parceria com o poder público, que foi criando condições para atender aos anseios do setor privado em detrimento dos interesses coletivos desde a sua fundação, no qual o poder público justifica a atuação das classes hegemônicas na cidade.

Ao analisar os investimentos recebidos por meio do Governo Federal destinado ao PAC - Contorno Norte, percebe-se que o projeto foi executado às pressas, na medida em que o poder público municipal percebeu a disponibilidade de tais recursos, sem que fosse realizado um novo projeto e estudado os seus reflexos no cotidiano de muitos moradores.

Assim, os moradores buscaram novas formas de se adaptar frente a uma obra de grande magnitude. Como reflexo dessa obra, ocorreram mudanças nas relações sociais dos moradores, diminuição da qualidade de vida, dificuldade de acesso aos principais serviços públicos, além de ter que conviver com os ruídos e a poluição constante provenientes da via Contorno Norte. 
Com os dados obtidos em termos de produção do espaço local foi possível averiguar que o planejamento urbano passa a ser instrumento para estratégias capitalistas a fim de viabilizar grandes obras. E, dessa forma, as alianças são ferramentas para que os agentes envolvidos viabilizem seus projetos travestidos da ideia que o benefício é coletivo, porém, o que se percebeu foi que esse projeto trouxe reflexos negativos na produção local.

E, considerando a territorialização, desterritorialização e reterritorialização, pode-se dizer que esta pesquisa foi essencial para se entender especificamente no Contorno Norte, quais foram as relações entre as modificações realizadas no território e como isso impactou na vida das pessoas que são diretamente afetadas por elas. Evidenciou-se, de modo geral, os reflexos que a obra teve na vida cotidiana dos moradores residentes nas imediações e como eles construíram suas reterritorializações.

Acredita-se que as dinâmicas que contemplam a T-D-R podem ainda ser mais bem exploradas, visto que o Contorno Norte conta com uma extensa área territorial e a presente pesquisa limitou-se a analisar somente dois bairros (Conjunto Hortência e Conjunto Thais). Neste sentido, existe a possibilidade de analisar os diversos investimentos realizados pelo PAC em Maringá, relacionados à transparência quanto aos projetos e valores para execução, participação da comunidade nas decisões dos projetos e os reflexos na vida das pessoas que sofrem com as intervenções urbanísticas justificadas como planejamento urbano.

Como estudo futuro, espera-se que a pesquisa sobre territórios possa ser explorada dentro dos conceitos de T-D-R, analisando-se, assim, as interações entre a forma como as pessoas se organizam e os interesses de capital, avançando no sentido de se compreender as dinâmicas territoriais e as relações que se estabelecem nas esferas políticas, econômicas e culturais. Assim, espera-se que essa pesquisa contribua com a tarefa que tem os Estudos Organizacionais em contribuir com o entendimento de como esses processos refletem na organização territorial das cidades por meio de intervenções urbanas.

\section{REFERÊNCIAS}

ANDRADE, Carlos Roberto Monteiro de; CORDOVIL, Fabíola Castelo de Souza. A cidade de Maringá, PR. o plano inicial e as "requalificações urbanas". In: COLOQUIO INTERNACIONAL DE GEOCRÍTICA, 10., 2008. Actas [...]. Universidade de Barcelona, 2008. Disponível em: http://www. ub.edu/geocrit/-xcol/55.htm. Acesso em: 01 set. 2014.

BARDIN, L. Análise de conteúdo. Lisboa: Edições 70, 1979.
BAUER, Martin W.; AARTS, Bas. A construção do corpus: um princípio para a coleta de dados qualitativos. In: BAUER, Martin W.; GASKELL, George (Orgs.). Pesquisa qualitativa com texto, imagem e som: um guia prático. 11. ed. Petrópolis: Vozes, 2013. p. 39-63.

BRASIL. Programa de Aceleração do Crescimento. 2015. Disponível em: www.pac.gov.br. Acesso em 15 de Jun.2015. 


\section{REFERÊNCIAS}

CARLOS, Ana Fani Alessandri. A cidade. São Paulo: Contexto, 1999.

CARLOS, Ana Fani Alessandri; SOUZA, Marcelo Lopes de; SPOSITO, Maria Encarnação Beltrão (Orgs.). A produção do espaço urbano: agentes e processos; escalas e desafios. São Paulo: Contexto, 2013.

CARLOS, Ana Fani Alessandri. Da "organização" à "produção" do espaço no movimento do pensamento geográfico. In: CARLOS, Ana Fani Alessandri; SOUZA, Marcelo Lopes de; SPOSITO, Maria Encarnação Beltrão (Orgs.). A produção do espaço urbano: agentes e processos; escalas e desafios. São Paulo: Contexto, 2013. p. 53-73.

COELHO, Kellen da Silva. A resistência à nova proposta de Plano Diretor apresentada pela Prefeitura Municipal de Florianópolis: uma análise das práticas alternativas de organizar. 2012. 358 f. Tese (Doutorado em Administração) - Programa de Pós-Graduação em Administração, Universidade Federal de Santa Catarina, Florianópolis, 2012.

CORRÊA, Roberto Lobato. O espaço urbano. São Paulo: Ática, 1989.

CORRÊA, Roberto Lobato. Sobre agentes sociais, escala e produção do espaço: um texto para discussão. In: CARLOS, Ana Fani Alessandri; SOUZA, Marcelo Lopes de; SPOSITO, Maria Encarnação Beltrão (Orgs.). A produção do espaço urbano: agentes e processos; escalas e desafios. São Paulo: Contexto, 2013. p. 41-51.
FLICK, Uwe. Uma introdução à pesquisa qualitativa. Tradução: Sandra Netz. 2. ed. Porto Alegre: Artmed, 2004.

FONTANA, Felipe, VALLOTA, Fernanda Martins. Projeto "PAC" Contorno Norte de Maringá: os impactos da obra e o aprofundamento do processo de segregação socioespacial na região metropolitana de Maringá. Revista Espaço Acadêmico. 2014.

HAESBAERT, Rogério. O mito da desterritorialização e as "regiões-rede". Anais do V Congresso Brasileiro de Geografia. Curitiba: AGB, 1994.

HAESBAERT, Rogério. O Mito da Desterritorialização. Rio de Janeiro: Bertrand Brasil, 2004.

HAESBAERT, Rogério. Concepções de território para entender a desterritorialização. In: SANTOS, Milton; BECKER, K. Bertha. Território, territórios: ensaios sobre o ordenamento territorial. Rio de Janeiro: Lamparina, 2007.

HAESBAERT, Rogério. Desterritorialização: entre as redes e os aglomerados de exclusão. In: CASTRO, Iná Elias de; GOMES, Paulo Cesar da Costa; CORRÊA, Roberto Lobato. Geografia: conceitos e temas. 15. ed. Rio de Janeiro: Bertrand Brasil, 2012. p. 165-205.

INSTITUTO BRASILEIRO DE GEOGRAFIA E ESTATÍSTICA. Censo 2010. Disponível em: www. ibge.gov.br. Acesso em: 20 jun. 2015. 


\section{REFERÊNCIAS}

LEFÈBVRE, Henri. La production de l'espace. Paris: Antrophos, 1974.

LEITÃO, Gerônimo. A construção do eldorado urbano: o plano diretor da Barra da Tijuca e Baixada de Jacarepaguá, 1970/1988, Niterói: Eduff, 1999.

MINAYO, Maria Cecilia de Souza. Pesquisa social: teoria método e criatividade. 5 ed. Petrópoles, RJ. Vozes, 2009.

RAFFESTIN, Claude. Por uma geografia do poder. São Paulo: Ática, 1993.

RODRIGUES, Ana Lúcia et al. Observatório das Metrópoles: região metropolitana de Maringá. Disponível em: http://www.cch.uem.br/observatorio/index.php?option=com_content\&view $=$ section\&id=3\&ltemid=53. Acesso em: 23 jul. 2015.

SANTOS, Milton. O retorno do território. In: SANTOS, M. et al. (Orgs.). Território: globalização e fragmentação. São Paulo: Hucitec/Anpur, 1994.

SAQUET, Marcos A. Por uma abordagem territorial. In: SAQUET, Marcos A.; SPOSITO, Eliseu S. (Orgs.) Territórios e territorialidades: teorias, processos e conflitos. São Paulo: Expressão Popular, 2009. p. 73-94.
SAQUET, Marcos A. As relações de poder e os significados do conceito de território. In:

SAQUET, Marcos A. Abordagens e concepções de território. São Paulo: Outras Expressões, 2013. p. 27-35.

SOUZA, Marcelo Lopes de. O território: sobre espaço e poder, autonomia e desenvolvimento. In: CASTRO, Iná Elias de; GOMES, Paulo Cesar da Costa; CORRÊA, Roberto Lobato. Geografia: conceitos e temas. 15. ed. Rio de Janeiro: Bertrand Brasil, 2012. p. 77-116.

STAHLHOEFER, Julia Marcon Costa; RODRIGUES, Ana Lúcia. (Des)articulações territoriais urbanas: a privatização de áreas públicas. In: Simpósio Paranaense de Estudos climáticos, 2., 2010, Maringá. Anais... Maringá, Universidade Estadual de Maringá, 2010.

TÖWS, Ricardo Luiz. Grandes projetos como reprodução da lógica do capital em Maringá (PR). 359 f. Tese (Doutorado em Geografia) - Programa de Pós-Graduação em Geografia, Universidade Estadual de Maringá, Maringá, 2015. 